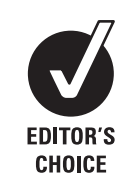

CHOICE

\title{
Quitting cigarettes completely or switching to smokeless tobacco: do US data replicate the Swedish results?
}

\author{
S-H Zhu, ${ }^{1}$ J B Wang, ${ }^{1}$ A Hartman, ${ }^{2}$ Y Zhuang, ${ }^{1}$ A Gamst, ${ }^{1}$ J T Gibson, ${ }^{3}$ H Gilljam, ${ }^{4}$ \\ M R Galantit
}

${ }^{1}$ University of California, San Diego, California, USA;

${ }^{2}$ National Cancer Institute;

${ }^{3}$ Information Management Services, Rockville, Maryland, USA; ${ }^{4}$ Karolinska Institutet,

Stockholm, Sweden

Correspondence to: Dr Shu-Hong Zhu, Department of Family and Preventive Medicine, University of California, San Diego, 9500 Gilman Drive 0905, La Jolla, CA 92093-0905, USA; szhu@ucsd.edu

Received 17 October 2008 Accepted 8 January 2009 Published Online First

23 January 2009

\begin{abstract}
Background: Swedish male smokers are more likely than female smokers to switch to smokeless tobacco (snus) and males' smoking cessation rate is higher than that of females. These results have fuelled international debate over promoting smokeless tobacco for harm reduction. This study examines whether similar results emerge in the United States, one of few other western countries where smokeless tobacco has long been widely available.

Methods: US data source: national sample in Tobacco Use Supplement to Current Population Survey, 2002, with 1-year follow-up in 2003. Analyses included adult selfrespondents in this longitudinal sample ( $n=15$ 056). Population-weighted rates of quitting smoking and switching to smokeless tobacco were computed for the 1-year period.
\end{abstract}

Results: Among US men, few current smokers switched to smokeless tobacco $(0.3 \%$ in 12 months). Few former smokers turned to smokeless tobacco (1.7\%). Switching between cigarettes and smokeless tobacco, infrequent among current tobacco users $(<4 \%)$, was more often from smokeless to smoking. Men quit smokeless tobacco at three times the rate of quitting cigarettes $(38.8 \%$ vs $11.6 \%, p<0.001)$. Overall, US men have no advantage over women in quitting smoking $(11.7 \%$ vs $12.4 \%$, $p=0.65)$, even though men are far likelier to use smokeless tobacco.

Conclusion: The Swedish results are not replicated in the United States. Both male and female US smokers appear to have higher quit rates for smoking than have their Swedish counterparts, despite greater use of smokeless tobacco in Sweden. Promoting smokeless tobacco for harm reduction in countries with ongoing tobacco control programmes may not result in any positive population effect on smoking cessation.

One of the most controversial issues in the debate on tobacco harm reduction is whether the public health community should promote smokeless tobacco as a safer alternative to smoking. Proponents of the idea argue that many smokers cannot or will not quit. Thus, encouraging them to switch to smokeless tobacco products, which are less harmful than cigarettes even though still carrying significant health risks, would reduce the overall disease burden of tobacco use. ${ }^{1-4}$ Those who oppose or have reservations about wider use of smokeless tobacco are concerned that promoting smokeless tobacco as a safer product would dilute the overall anti-tobacco message, ${ }^{4-7}$ creating a negative net impact compared to continuing current, proved tobacco control strategies. ${ }^{8}$ It is difficult to gauge the likelihood of either scenario because both arguments involve assumptions about population behaviour, and empirical data to verify them are hard to obtain.

The strongest population data so far have come from one country, Sweden. A particular smokeless tobacco product, snus, long popular among Swedish males, enjoyed a major sales increase beginning in the 1970s. ${ }^{9-11}$ Studies have found the increased use of snus among Swedish men is associated with a greater drop in smoking prevalence among men than among women. ${ }^{11}{ }^{12}$ This drop is further credited with contributing to a faster than expected drop in men's lung cancer rate. ${ }^{11}$ The harm reduction effects of snus in Sweden appear strong. It would seem logical to encourage harm reduction via smokeless tobacco in other countries as well.

There are, however, difficulties in directly applying the Swedish results to other countries. Many have cautioned that the Swedish results could be a country-specific phenomenon because of unique historical and cultural factors associated with snus use. ${ }^{513}{ }^{14}$ Cultural differences notwithstanding, there are conceptual ambiguities involved in interpreting the results. First, it is not well quantified how much of the greater drop in smoking prevalence among Swedish men comes from current smokers switching to snus and how much from new tobacco users taking up snus instead of cigarettes. ${ }^{14}$ Second, it is unclear how much of the increased use of snus is the result of price; snus traditionally costs far less than cigarettes. ${ }^{15}$ Third, it is unclear how much of the increase in snus use is related to smokers' perception that snus is safer, since safety has historically not been the chief promotional message for snus in Sweden. ${ }^{9}{ }^{16} 17$ If the increase in use is mainly a response to price differential, or to social or cultural factors beyond a perception of harm reduction, then applicability of the Swedish results to other countries becomes uncertain.

An added difficulty in assessing international implications of the Swedish data is the dearth of relevant data from other countries. Sale of smokeless tobacco is banned in Australia, New Zealand and European Union countries other than Sweden, so there is little usage data on which to base predictions. In Norway, a non-EU country with no ban, snus use is increasing. ${ }^{18}$ In the United States, where there is no ban and the tobacco industry promotes all tobacco products, the prevalence of use of smokeless tobacco has declined along with 
smoking, until very recently. ${ }^{19} 20$ These conflicting data make it hard to predict the results of promoting smokeless tobacco as a safer alternative to cigarettes, especially if the message were to come from public health authorities as well as from the tobacco industry.

The present study aims to provide empirical results to facilitate the discussion by examining data from the United States, where smokeless tobacco products have long been widely available, as in Sweden. The study focuses on the relation between the use of smokeless tobacco and smoking cessation.

To put the study in perspective, it is important to articulate the logic behind the claim that snus helps Swedish smokers quit smoking. To summarise: In Sweden, snus is far more popular among men than among women. Assuming that the need for nicotine is the chief cause of relapse, men should have an advantage over women in quitting smoking, because snus gives men an alternative source of nicotine. However, if cessation of both smoking and snus is considered, men and women should show similar rates. Therefore, a key test for the snus effect would be two-pronged: a sex difference in smoking cessation rates and a lack of sex difference in total tobacco cessation rates. These are precisely the results found in a longitudinal study based on the well-known MONICA project in northern Sweden. ${ }^{21}$ The annual smoking cessation rate, averaged over many years of follow-up, was $50 \%$ higher for male smokers than for female smokers (6.0\% vs $4.1 \%$ ). However, the annual quit rate for both cigarettes and snus was no different for males and females (3.8\% vs $3.6 \%$ ). A longitudinal study in southern Sweden, where the sex difference in snus use is less pronounced than in the north, also found that a significantly higher proportion of males than females quit smoking (30\% higher for males). ${ }^{22}$ These results support the position that snus helps Swedish men quit smoking. Finding similar data patterns from other countries would suggest that smokeless tobacco could also have the same effect in those countries.

We analyse newly available longitudinal data based on a US national survey: the Tobacco Use Supplement (TUS) to the Current Population Survey (CPS). The longitudinal design allows examination of both switching and quitting at the population level, avoiding some of the methodological pitfalls of cross-sectional studies. ${ }^{23}$ The present study asks three related questions. First, how many US smokers switch from smoking to smokeless tobacco in a given year? Second, since use of smokeless tobacco in the United States is chiefly a male behaviour, ${ }^{19}$ is men's smoking cessation rate significantly higher than women's? Third, are sex differences in cessation rate, if any, sustained when the analysis considers quitting both cigarettes and smokeless tobacco?

\section{METHODS}

\section{Data sources}

The TUS-CPS is a series of large US national household surveys administered by the Census Bureau for the National Cancer Institute (NCI), providing data on tobacco use behaviour. ${ }^{24} 25$ The CPS, a monthly Census Bureau survey for the Bureau of Labor Statistics, uses a multistage stratified area probability sample of households for the civilian non-institutionalised population $\geqslant 15$ years old. ${ }^{26}$ The TUS-CPS is conducted with eight panel rotations in three waves, each covering all 50 US states. $^{24} 25$

The present study used a longitudinal sample between two TUS-CPSs: TUS-CPS 2002, which collected data in June 2001, November 2001 and February 2002, and TUS-CPS 2003, which collected data in February, June and November 2003. ${ }^{24} 25$ Owing to the rotating panel design of the CPS, a third of those interviewed in February 2002, across all US states, were interviewed again in February 2003. ${ }^{27}$ This creates a unique opportunity for examining tobacco use behaviour with a longitudinal study design of 1 year's duration, based on a national sample. ${ }^{27} 29$

Detailed methodology for the TUS-CPS sampling design can be found in web-accessible technical reports. ${ }^{25} 2829$ The response rate for TUS-CPS 2002 was $82.5 \%$. However, $22.5 \%$ of these surveys were answered by proxy (someone in the same household as the person selected for interview). ${ }^{24}{ }^{25}$ Our analysis focuses on the 2002-3 longitudinal portion. It excludes proxies, respondents under age 18 , and those who reported being current

Table 1 Demographics of study sample at baseline (2002)

\begin{tabular}{|c|c|c|c|c|}
\hline & $\begin{array}{l}\text { Cigarettes only } \\
(\%)(95 \% \mathrm{CI})\end{array}$ & $\begin{array}{l}\text { Smokeless only } \\
(\%)(95 \% \mathrm{CI})\end{array}$ & $\begin{array}{l}\text { Cigarettes and smokeless } \\
(\%)(95 \% \mathrm{CI})\end{array}$ & $\begin{array}{l}\text { Neither cigarettes nor } \\
\text { smokeless } \\
(\%)(95 \% \mathrm{CI})\end{array}$ \\
\hline & $(n=2565)$ & $(n=258)$ & $(n=53)$ & $(n=12116)$ \\
\hline \multicolumn{5}{|l|}{ Gender } \\
\hline Male & 53.1 (51.0 to 55.2 ) & 91.7 (85.5 to 95.4 ) & 92.8 (80.0 to 97.6$)$ & 45.8 (45.2 to 46.4$)$ \\
\hline Female & 46.9 (44.8 to 49.0$)$ & $8.3(4.6$ to 14.5$)$ & $7.2(2.4$ to 20.0$)$ & 54.2 (53.6 to 54.8 ) \\
\hline \multicolumn{5}{|l|}{ Age (years) } \\
\hline $18-24$ & $12.0(9.9$ to 14.5$)$ & $8.3(3.7$ to 17.6$)$ & 10.1 (3.1 to 28.3 ) & $11.6(10.9$ to 12.3$)$ \\
\hline $25-44$ & 46.1 (43.4 to 48.8 ) & 55.1 (46.0 to 64.0 ) & 62.5 (45.3 to 77.0$)$ & 39.9 (39.1 to 40.6$)$ \\
\hline $45-64$ & 34.3 (32.0 to 36.7$)$ & 23.4 (17.2 to 31.1$)$ & $22.4(12.4$ to 37.0$)$ & $31.3(30.6$ to 31.9$)$ \\
\hline $65+$ & $7.6(6.5$ to 9.0$)$ & $13.1(9.1$ to 18.6$)$ & $5.0(0.7$ to 28.2$)$ & $17.3(16.9$ to 17.8$)$ \\
\hline \multicolumn{5}{|l|}{ Ethnicity } \\
\hline White & 78.5 (76.3 to 80.5$)$ & 86.5 (77.8 to 92.2 ) & 85.8 (71.3 to 93.6$)$ & 70.7 (70.0 to 71.5$)$ \\
\hline Hispanic & $7.6(6.0$ to 9.6$)$ & $3.6(1.2$ to 10.5$)$ & $3.2(0.7$ to 12.9$)$ & $12.5(12.0$ to 13.2$)$ \\
\hline Black & 11.2 (9.7 to 12.9$)$ & $8.2(4.4$ to 14.7$)$ & $5.7(1.2$ to 23.5$)$ & $11.5(11.0$ to 12.0$)$ \\
\hline Asian & 1.8 (1.1 to 2.8$)$ & 0 & 0 & 4.7 (4.2 to 5.1$)$ \\
\hline American Indian & $1.0(0.6$ to 1.7$)$ & $1.7(0.6$ to 5.1$)$ & $5.3(1.3$ to 19.3$)$ & $0.6(0.4$ to 0.8$)$ \\
\hline \multicolumn{5}{|l|}{ Education (years) } \\
\hline$\leqslant 12$ & 57.5 (54.7 to 60.3$)$ & 60.1 (51.4 to 68.3$)$ & $63.4(44.9$ to 78.6$)$ & $43.6(42.2$ to 44.0$)$ \\
\hline$>12$ & 42.5 (39.7 to 45.3$)$ & 39.9 (31.7 to 48.7$)$ & $36.7(21.4$ to 55.1$)$ & 56.4 (55.1 to 57.8$)$ \\
\hline
\end{tabular}

All percentages weighted by population parameters. 
Table 2 Changes in cigarette and smokeless tobacco use among US current tobacco users from 2002 to 2003 , by sex

\begin{tabular}{|c|c|c|c|c|c|c|c|}
\hline \multirow[b]{2}{*}{2002 Status } & \multirow[b]{2}{*}{ No } & \multicolumn{6}{|l|}{2003 Status } \\
\hline & & $\begin{array}{l}\text { Cigarettes only } \\
(\%)(95 \% \mathrm{CI})\end{array}$ & $\begin{array}{l}\text { Smokeless only } \\
\text { (\%) }(95 \% \mathrm{CI})\end{array}$ & $\begin{array}{l}\text { Cigarettes and } \\
\text { smokeless } \\
(\%)(95 \% \mathrm{Cl})\end{array}$ & $\begin{array}{l}\text { Neither cigarettes } \\
\text { nor smokeless } \\
(\%)(95 \% \text { Cl) }\end{array}$ & $\begin{array}{l}\text { Quit cigarettes } \\
\text { (\%) (95\% Cl) }\end{array}$ & $\begin{array}{l}\text { Quit smokeless } \\
\text { (\%) (95\% CI) }\end{array}$ \\
\hline \multicolumn{8}{|l|}{ Male } \\
\hline Cigarettes only & 1105 & 86.2 (83.1 to 88.9 ) & $0.3(0.1$ to 0.8$)$ & $2.2(1.4$ to 3.5$)$ & 11.3 (8.7 to 14.2 ) & $11.6(9.1$ to 14.6$)$ & - \\
\hline Smokeless only & 234 & $3.9(1.4$ to 10.6$)$ & 59.4 (50.6 to 67.7$)$ & $1.8(0.6$ to 5.5$)$ & $35.0(27.0$ to 43.8$)$ & - & 38.8 (30.5 to 47.9$)$ \\
\hline Cigarettes and smokeless & 48 & $37.0(23.2$ to 53.4$)$ & $4.9(0.9$ to 23.1$)$ & $45.0(29.7$ to 61.3$)$ & 13.1 (4.9 to 30.7$)$ & 18.0 (7.8 to 36.2$)$ & 50.1 (34.5 to 65.7$)$ \\
\hline \multicolumn{8}{|l|}{ Female } \\
\hline Cigarettes only & 1394 & 87.6 (85.2 to 89.7 ) & 0 & $0.1(0.0$ to 0.2$)$ & $12.3(10.2$ to 14.7$)$ & 12.3 (10.2 to 14.7$)$ & - \\
\hline Smokeless only & 24 & $3.2(0.2$ to 31.5$)$ & 52.7 (27.4 to 76.7$)$ & 0 & 44.1 (22.2 to 68.6$)$ & - & 47.3 (23.4 to 72.6$)$ \\
\hline Cigarettes and smokeless & 5 & $71.6(14.0$ to 97.5$)$ & 0 & $28.4(2.5$ to 86.0$)$ & 0 & 0 & 71.6 (14.0 to 97.5$)$ \\
\hline
\end{tabular}

All percentages weighted by population parameters.

smokers in 2002 but then stated that they had never smoked when surveyed in 2003 (1.9\% of the sample). This results in an effective sample size of 15056 for the longitudinal analysis.

The exclusion of proxies from the analysis is based on the consideration that their report of tobacco use is less accurate when they are reporting on smokers who consume cigarettes on a non-daily basis or who have recently quit. ${ }^{30}$ This inaccuracy can lead to a bias in estimation of quit rates because it affects both the number considered smokers in the baseline survey (the denominator) and the number considered quitters in the followup survey (the numerator). It should be mentioned, however, that the inclusion of proxies does not change the results of this study (interested readers can download the data from the cited sources ${ }^{24} 25_{27}^{28}$ and repeat the analytical procedure outlined below, with proxies included). Since most cessation studies exclude proxies, this study chooses to exclude them also, to avoid complicating the main question: Do smokers switch to smokeless tobacco?

\section{Measures}

Smokers are defined as "having smoked at least 100 cigarettes in their lifetime" and at the time of the survey "smoking cigarettes every day or some days." Smokeless tobacco users are defined as "using chewing tobacco or snuff every day or some days" at the time of survey. Thus, tobacco users are categorised into three groups: cigarette smokers only; users of smokeless tobacco only; and dual users.

Non-smokers are grouped into never-smokers ("never smoked 100 cigarettes in their lifetime") and former smokers ("smoked at least 100 cigarettes in their lifetime but not smoking at all at time of survey"). Because history of smokeless tobacco use was not well assessed, we created no subgroups for respondents not using smokeless tobacco at the time of survey.

In the longitudinal sample, tobacco use status could change from 2002 to 2003. A change from "yes" to "no" in response to tobacco use questions is defined as having quit. A tobacco user in 2002 could have quit smoking, quit using smokeless tobacco or quit both in 2003. Similarly, 2002 non-smokers could become smokers, smokeless tobacco users or dual users in 2003.

\section{Analysis}

All results were analysed separately for males and females. Percentages were weighted by census-derived weights for the appropriate survey years. ${ }^{25} 28$ Confidence intervals were obtained with the jack-knife method, ${ }^{31}$ with the special replicate-weights developed for the longitudinal 2002-2003 TUS-CPS. ${ }^{29}$ All computations were performed with SAS 9.1, ${ }^{32}$ and confidence intervals estimated with SUDAAN 9.1.33

\section{RESULTS}

Table 1 reports the demographic characteristics of the study sample at baseline, grouped into exclusive smokers, exclusive smokeless tobacco users, dual users and non-users. The sex difference is most notable among smokeless tobacco users: over $90 \%$ were male. Smokeless tobacco users also tended to be younger, white and less educated.

Among male tobacco users in 2002, 83.0\% were exclusive smokers and $17.0 \%$ used smokeless tobacco (14.1\% exclusive smokeless tobacco users and $2.9 \%$ dual users). Among female tobacco users, $98.0 \%$ were exclusive smokers, $1.7 \%$ exclusive smokeless tobacco users and $0.3 \%$ dual users (data not shown in table 1).

Table 2 shows changes in tobacco use from 2002 to 2003, by sex. Among males who exclusively smoked cigarettes in 2002 , $86.2 \%$ still exclusively smoked cigarettes in 2003 , and $0.3 \%$ had quit smoking and switched to smokeless tobacco. Another $2.2 \%$ became dual users. The rest, $11.3 \%$, quit cigarettes and used no smokeless tobacco. If only quitting smoking is considered, then $11.6 \%$ had quit by 2003 (italicised in table).

Among males using only smokeless tobacco in 2002, 59.4\% continued exclusive use in 2003, and 3.9\% quit smokeless tobacco and switched to cigarettes. Another 1.8\% became dual users. The rest $(35.0 \%)$ quit smokeless tobacco and used no cigarettes. If only quitting smokeless tobacco is considered, then $38.8 \%$ had quit.

Among males using both cigarettes and smokeless tobacco in $2002,45 \%$ continued to use both. Of the rest, $37.0 \%$ continued smoking but quit smokeless tobacco, $4.9 \%$ continued using smokeless tobacco but quit smoking and $13.1 \%$ quit both smoking and smokeless tobacco. Overall, 18.0\% quit smoking and $50.1 \%$ quit smokeless tobacco.

Three things stand out in the top panel of table 2. First, the quit rate was significantly lower for smoking than for smokeless tobacco. This held true when comparing exclusive cigarette smokers with exclusive smokeless tobacco users $(11.6 \%$ vs $38.8 \%$ ) and for dual users (18.0\% vs $50.1 \%$ ). Second, and related, the data on the diagonal show decreasing stability of tobacco use status: exclusive cigarette use was more stable than exclusive smokeless tobacco use, and exclusive smokeless tobacco use more stable than dual use. Third, quitting one form of tobacco and switching to another was infrequent. If there was a switch, it was more likely to be from smokeless tobacco to cigarettes than vice versa ( $3.9 \%$ vs $0.3 \%$ ).

The bottom panel of table 2 presents results for females. The data exhibit the same pattern as for males, except that most females were exclusively cigarette smokers. The quit rate for the few females who used smokeless tobacco was significantly 


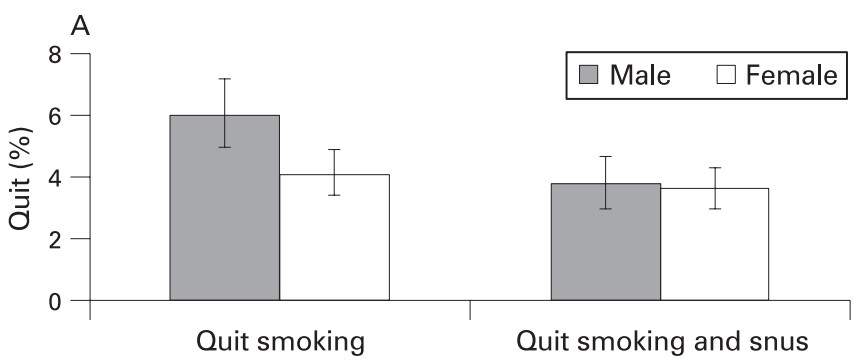

Based on multi-year follow up results reported in tables 3-5 in Rodu et al. (2003)

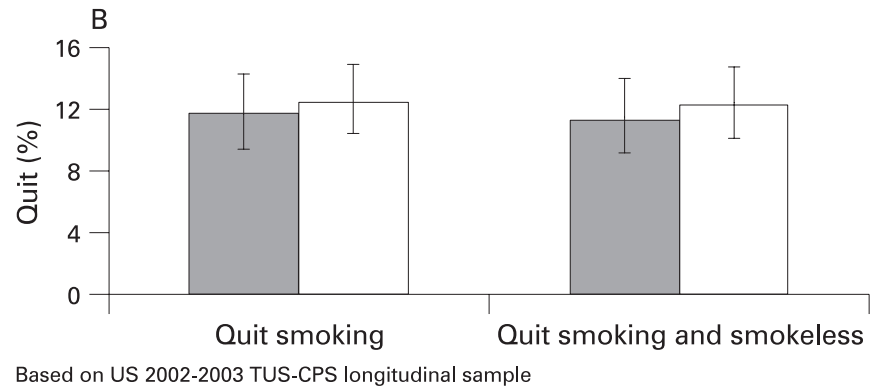

Figure 1 (A) Annual quit rate for smoking or for smoking and snus in MONICA Project (5-13 years), Sweden. (B) Percentage of 2002 smokers who quit smoking or quit both smoking and smokeless in 2003, United States.

higher $(47.3 \%)$ than the quit rate for smoking $(12.3 \%$, $\mathrm{p}<0.01)$. The very few dual users did not quit smoking at all, but did have a high quit rate for smokeless tobacco $(71.6 \%)$.

Figure 1 shows the data for the two-pronged test for sex differences. For comparison, the Swedish results based on the MONICA project ${ }^{21}$ are summarised in figure 1A. Swedish male smokers' quit rate was $50 \%$ higher than female smokers' $(6.0 \%$ vs $4.1 \%, \mathrm{p}<0.01)$, but the sex difference disappears when quitting both smoking and snus is considered $(3.8 \%$ vs $3.6 \%$, $\mathrm{p}=0.63$ ). The US data (fig1B) show a very different pattern: there is no sex difference in quitting smoking: $11.7 \%$ for males and $12.4 \%$ for females $(p=0.65)$. Nor is there a sex difference for quitting both smoking and smokeless tobacco: $11.3 \%$ vs $12.3 \%(p=0.58)$.

If the more stringent criterion of "having quit smoking for at least 6 months," is used for the US data, then the quit rates are $7.6 \%$ and $6.6 \%$ for males and females, respectively ( $p=0.43$; not shown in fig 1). Because the survey follow-up period was only 1 year, it is not feasible to calculate a rate for "having quit for at least 12 months."

Since the diverse ethnic groups in the United States vary in tobacco use prevalence, we examine whether ethnicity confounds the results. When the calculation is limited to US white people, the pattern remains the same. There is no significant sex difference: the smoking cessation rate was $11.5 \%$ for white males and $12.2 \%$ for white females, and the rates of "having quit for at least 6 months" were $6.8 \%$ for white males and $6.5 \%$ for white females.

Table 3 examines those who were not using tobacco in 2002. Former smokers were divided into those abstinent for $\leqslant 1$ year (recent former smokers) and those abstinent for longer than 1 year. Among male recent former smokers, $1.7 \%$ turned to smokeless tobacco in 2003, whereas $24.4 \%$ relapsed to cigarettes. Among males abstinent longer than 1 year, $0.3 \%$ turned to smokeless tobacco use, whereas $2.6 \%$ relapsed to cigarettes. Never-smokers were more likely to take up smoking than smokeless tobacco: $2.5 \%$ vs $0.7 \%$. The same data pattern held for women.

\section{DISCUSSION}

This longitudinal study of the US population found that few male smokers stopped smoking and switched to smokeless tobacco $(0.3 \%$ in 1 year) and few former smokers turned to smokeless tobacco $(1.7 \%)$. If anything, it was more likely for smokeless tobacco users to switch to cigarettes. Smoking was the more stable tobacco use status, as the quit rate for smokeless tobacco was three times higher than for smoking. Men's smoking cessation rate was no higher than women's $(11.7 \%$ vs $12.4 \%$ ) even though men were much more likely to use smokeless tobacco.

The Swedish data pattern was just the opposite. ${ }^{21}{ }^{34}$ The rate of switching from cigarettes to smokeless tobacco was greater than the rate of switching from smokeless tobacco to cigarettes, and using smokeless tobacco was the more stable tobacco use status. Moreover, Swedish men were significantly more likely than Swedish women to quit smoking in any given year. ${ }^{21}$ Clearly, the Swedish data pattern is not replicated in the United States, even though both countries have a long history of smokeless tobacco use and promotion of smokeless tobacco by tobacco industries.

One reason that the Swedish data pattern is not replicated in the United States could be that in the United States smokeless tobacco has not been promoted as a safer alternative to cigarettes. However, neither has snus been widely promoted in Sweden as safer. ${ }^{16}{ }^{17}$ In fact, the international scientific community has only recently begun to examine the relative risks. ${ }^{35}$ Generally, smokers are uninformed about relative risks, ${ }^{37}$ an issue that the public health community still must address. ${ }^{38}$

There has been little documented comparison of the tobacco industries' strategies for promoting snus in Sweden and smokeless tobacco in the United States. What is clear is that the Swedish tobacco industry succeeded in shifting snus use from a limited segment of the male population in the 1970s to the more general male population by the 1990s. ${ }^{911}$ No similar shift has taken place in the United States, perhaps in part because of the product differences between Swedish snus and most US smokeless tobacco products. ${ }^{11}$

Another explanation could be cost differential. In Sweden, until 2008, an average snus user spent about $25 \%$ of what an average cigarette smoker spent on tobacco products..$^{15}$ The price difference in the United States is much smaller. ${ }^{5}$ In the United States, an average smokeless tobacco user spends about $50-60 \%$ of what an average smoker spends on tobacco products. ${ }^{20}{ }^{39} 40$ If cost is the key factor, then it will become apparent with time, as the increasing cost differential between cigarettes and smokeless tobacco in the United States causes more smokers to switch to smokeless tobacco, ${ }^{20}$ independently of their perception of relative risks. Of course it may be that, culturally, smokeless tobacco use in the United States is so different from snus use in Sweden that US smokers are unlikely to switch to smokeless tobacco without an aggressive public health campaign. Even in Sweden, the appeal of snus has long been limited to men, suggesting powerful cultural influences. ${ }^{11}$

Beyond issues of promotion and cost, one might argue that use of smokeless tobacco must be sufficiently widespread in a given population before smokers will consider switching: The proportion of smokeless tobacco users among all male tobacco users in the United States is low (17\%), and more US men might have to be using smokeless tobacco before more smokers will switch to smokeless tobacco. This possibility, admittedly tautological, merits consideration. There are some relevant US data, as the prevalence of use of smokeless tobacco varies widely 
Table 3 Changes in cigarette and smokeless tobacco use from 2002 to 2003, among US former and never cigarette smokers, by sex

\begin{tabular}{|c|c|c|c|c|}
\hline \multirow[b]{2}{*}{2002 Status } & \multirow[b]{2}{*}{ No } & \multicolumn{3}{|l|}{2003 Status } \\
\hline & & $\begin{array}{l}\text { Cigarettes only } \\
\text { (\%) (95\% CI) }\end{array}$ & $\begin{array}{l}\text { Smokeless only } \\
\text { (\%) }(95 \% \mathrm{Cl})\end{array}$ & $\begin{array}{l}\text { Cigarettes and } \\
\text { smokeless } \\
(\%)(95 \% \mathrm{CI})\end{array}$ \\
\hline \multicolumn{5}{|l|}{ Male } \\
\hline \multicolumn{5}{|l|}{ Former smokers } \\
\hline Quit $\leqslant 1$ year & 172 & 24.4 (17.1 to 33.6$)$ & $1.7(0.5$ to 5.8$)$ & 0 \\
\hline Quit $>1$ year & 1624 & 2.6 (1.9 to 3.6$)$ & $0.3(0.1$ to 0.7$)$ & $0.1(0.0$ to 0.5$)$ \\
\hline Never smokers & 2867 & 2.5 (1.7 to 3.8 ) & $0.7(0.5$ to 1.1$)$ & 0.1 (0 to 0.3 ) \\
\hline \multicolumn{5}{|l|}{ Female } \\
\hline \multicolumn{5}{|l|}{ Former smokers } \\
\hline Quit $\leqslant 1$ year & 204 & 31.7 (24.9 to 39.3 ) & 0 & 0 \\
\hline Quit $>1$ year & 1697 & $2.9(2.1$ to 4.0$)$ & $0.3(0.1-0.6)$ & \\
\hline Never-smokers & 5383 & 1.7 (1.2 to 2.2 ) & 0 & 0 \\
\hline
\end{tabular}

All percentages weighted by population parameters.

across US states. ${ }^{41}$ In analysing another national survey (Zhu, unpublished results), we found that the percentage of smokers who reported using smokeless tobacco to aid smoking cessation was indeed associated with the prevalence of smokeless tobacco use in their states. However, the greater use of smokeless tobacco was not associated with higher population smoking cessation rates, in part owing to the lower use of nicotine replacement therapy in those same states. These results mean that greater use of smokeless tobacco may increase the likelihood of individual smokers switching to smokeless tobacco, but it is not a sufficient condition to increase population smoking cessation rates.

The data in table 2 probably provide a simpler explanation for the lack of smokeless tobacco effects in the United States: men quit smokeless tobacco at three times the rate of quitting cigarettes. As a result, smokeless tobacco is less useful for quitting smoking among US smokers because in all likelihood they would quit smokeless tobacco before they quit cigarettes. This would also lead to a lower rate of switching to smokeless tobacco and lower prevalence of smokeless tobacco use, compared to Swedish men.

Finally, the results shown in figure 1 offer additional explanations and may be particularly useful for policymakers in deliberating the merits of promoting smokeless tobacco use. Figure $1 \mathrm{~B}$ shows that US male smokers' quit rate is around $12 \%$, high enough to suffer a possible ceiling effect. How high would US men's quit rate climb if snus-like products were as widely used in the United States as in Sweden? If US male smokers were to attain a $50 \%$ higher quit rate than females, as in the Swedish MONICA study, then they would be quitting smoking at an annual rate of $18 \%$. One might reasonably question the likelihood of this. Moreover, the US smoking cessation rate, achieved through current tobacco control efforts, is equal on the population level for both men and women, unlike the Swedish results, which showed much lower quit rates for women than for men. ${ }^{2122}$

It is important to note that the present study examines broadscale population cessation rates. It does not address the question of whether smokeless tobacco has helped individual male smokers who used it to quit smoking. It is possible that US male smokers' cessation rate would be lower than that of female smokers if smokeless tobacco were not available. However, any positive smoking cessation effect of smokeless tobacco for individuals was apparently countered by other factors, such that its overall population effect could not be detected.
The strength of the present study is its longitudinal design with a national sample. The results are a needed addition to the empirical literature on the harm reduction debate, which has often relied on logical exercises rather than on data when addressing countries other than Sweden. However, the present study has a limited follow-up period (1 year). Future studies with longer follow-up will allow more comprehensive analysis of switching behaviour and better assessment of annual cessation rates. Also, the present study examines the effects of smokeless tobacco use on smoking cessation only, with very limited data on smoking uptake by adult never-smokers (table 3). Future longitudinal studies exploring this issue will be helpful.

The results of the present study of the US population do not directly refute the argument that promoting smokeless tobacco for harm reduction in countries with established tobacco control programmes will result in a large, positive population effect on smoking cessation. However, they provide little support for it. The argument remains a hypothesis, and it is weakened by these results.

\section{What is already known on this subject}

Data from Sweden show that male smokers are far likelier than female smokers to switch to smokeless tobacco (snus) and males' smoking cessation rate is significantly higher than that for females. These results appear to support the idea of promoting smokeless tobacco in other countries to reduce smoking-related diseases. However, no longitudinal data from other countries have been available to show the relation between smokeless tobacco use and smoking cessation rates outside Sweden.

\section{What this study adds}

Analysis of longitudinal data based on a national sample in the United States, one of few other Western countries where smokeless tobacco has long been widely available, found no discernable association between smokeless tobacco use and population smoking cessation rates. These results suggest that country-specific studies are needed before the global public health community engages in promoting smokeless tobacco as a way to increase smoking cessation rates. 
Acknowledgements: The authors would like to acknowledge Dr William W Davis of the Statistical Research Applications Branch of the Division of Cancer Control and Population Sciences/NCl for his development of the 2002-2003 overlap sample weights that were used in this study.

Funding: This work was supported in part by a supplemental grant to the University of California, San Diego Cancer Center from the National Cancer Institute (NCI): grant 5 P30 CA 23100-22S4 (to S-HZ). Findings and conclusions are those of the authors and do not reflect the views of the $\mathrm{NCl}$.

Competing interests: $\mathrm{HG}$, on behalf of his institution, has conducted clinical trials on smoking cessation with funding from Pharmacia, Pfizer, Glaxo-Smith-Kline and SanofiAventis and has also received compensation from the above-mentioned companies for lectures on prevention of tobacco use. Other authors declare no competing interests.

Ethics approval: This study has been approved by the ethics committee of the institutional review board, University of California, San Diego, Human Research Protection Program.

\section{REFERENCES}

1. Royal College of Physicians. Harm reduction in nicotine addiction: helping people who can't quit. A report by the Tobacco Advisory Group of the Royal College of Physicians. London: RCP, 2007.

2. Gartner CE, Hall WD, Vos T, et al. Assessment of Swedish snus for tobacco harm reduction: an epidemiological modeling study. Lancet 2007;369:2010-4.

3. Hatsukami DK, Henningfield JE, Kotlyar M. Harm reduction approaches to reducing tobacco-related mortality. Annu Rev Public Health 2004;25:377-95.

4. Stratton K, Shetty P, Wallace R, et al, eds. Committee to Assess the Science Base for Tobacco Harm Reduction, Institute of Medicine. Clearing the smoke: assessing the science base for tobacco harm reduction. Washington, DC: National Academy Press, 2001.

5. Hatsukami DK, Lemmonds C, Tomar S. Smokeless tobacco use: harm reduction or induction approach? Prev Med 2004;38:309-17.

6. Warner KE. Tobacco harm reduction: promise and perils. Nicotine Tob Res 2002;4(suppl):S2-71.

7. Hatsukami DK, Zeller M. The strategic dialogue on tobacco harm reduction: a vision and blueprint for action. Presented at the Society for Research on Nicotine and Tobacco 14th Annual Meeting, Portland, Oregon, February 2008

8. Glantz SA. Innovative approaches to harm reduction. Presented at the Society for Research on Nicotine and Tobacco 14th Annual Meeting, Portland, Oregon, February 2008.

9. Nordgren $\mathbf{P}$, Ramström L. Moist snuff in Sweden-tradition and evolution. Br J Addict 1990;85:1107-12.

10. Henningfield JE, Fagerström KO. Swedish Match Company, Swedish snus and public health: a harm reduction experiment in progress? Tob Control 2001;10:353-7.

11. Foulds $\mathbf{J}$, Ramström $\mathrm{L}$, Burke $\mathrm{M}$, et al. Effect of smokeless tobacco (snus) on smoking and public health in Sweden. Tob Control 2003:12:349-59.

12. Rodu B, Stegmayr B, Nasic S, et al. Impact of smokeless tobacco use on smoking in northern Sweden. J Intern Med 2002;252:398-404.

13. Gartner CE, Hall WD, Chapman S, et al. Should the health community promote smokeless tobacco (snus) as a harm reduction measure? PLoS Med 2007;30:1703-4.

14. Tomar SL, Connolly GN, Wilkenfeld J, et al. Declining smoking in Sweden: is Swedish Match getting the credit for Swedish tobacco control's efforts? Tob Control 2003;12:368-71.

15. Bask M, Melkersson M. Should one use smokeless tobacco in smoking cessation programs? Eur J Health Econ 2003;4:263-70.

16. Fagerström Karl-Olav. [karl.fagerstrom@swipnet.se], e-mail to SRNT listserve forum, 5 May 2007

17. Nordgren P. Swedish National Institute of Public Health [paul.nordgren@telia.com], personal e-mail 6 November 2008.

18. Helsedirektoratet [Norwegian Directorate of Health] (2008). Andel som bruker snus daglig eller av og til, menn 16-44 aar, 1985-2007 [Prevalence of daily and nondaily snus use, males 16-44 years old, 1985-2007]. http://shdir.no/tobakk/statistikk/ bruk av snus /bruk av snus (retrieved 15 Apr 2008).

19. Nelson DE, Mowery P, Tomar SL, et al. Trends in smokeless tobacco use among adults and adolescents in the United States. Am J Public Health 2006:96:897-905.
20. Connolly GN, Alpert HR. Trends in the use of cigarettes and other tobacco products, 2000-2007. JAMA 2008;299:2629-30.

21. Rodu B, Stegmayr B, Nasic S, et al. Evolving patterns of tobacco use in northern Sweden. J Intern Med 2003;253:660-5.

22. Lindström M, Isacsson S, et al. Smoking cessation among daily smokers, aged 4569: a longitudinal study in Malmo, Sweden. Addiction 2002;97:205-15.

23. Rodu B, Phillips CV. Switching to smokeless tobacco as a smoking cessation method: evidence from the 2000 National Health Interview Survey. Harm Reduct $J$ 2008:5:18.

24. Hartman AM, Willis G, Lawrence D, et al. The 2001-2002 Tobacco Use Supplement to the Current Population Survey (TUS-CPS): representative survey findings. 31 December 2004. http://riskfactor.cancer.gov/studies/tus-cps/results/data0102/ cps_results0102.pdf (accessed 15 May 2008)

25. US Department of Commerce, Census Bureau. National Cancer Institute and Centers for Disease Control and Prevention Co-sponsored Tobacco Use Supplement to the Current Population Survey (2001-2002). 2004. http://riskfactor.cancer.gov/ studies/tus-cps/. Data files (AND/OR) technical documentation (technical documentation website: http://www.census.gov/apsd/techdoc/cps/ cpsJun01Nov01Feb02.pdf)

26. US Census Bureau. Current population survey design and methodology technical paper 66. October 2006.http://www.bls.census.gov/cps/tp/tp66.htm laccessed 15 May 2008).

27. Hartman AM, Willis G, Davis WW, et al.). 2003 Tobacco Use Special Cessation Supplement to the Current Population Survey (TUSCS-CPS): representative survey findings. 12 October 2006. http://riskfactor.cancer.gov/studies/tus-cps/results/ data03/cps results03.pdf (accessed 15 May 2008).

28. US Department of Commerce, Census Bureau. National Cancer Institute and Centers for Disease Control and Prevention Co-sponsored Tobacco Use Specia Cessation Supplement to the Current Population Survey, 2003. 2006. http://riskfactor cancer.gov/studies/tus-cps/. Data files (and/or) technical documentation (technical documentation website: http://riskfactor.cancer.gov/studies/tus-cps/info.html).

29. Davis WW, Hartman AM, Gibson JT. Weighting the overlap sample obtained from two Tobacco Use Supplements to the Current Population Survey. October 2007. http:// riskfactor.cancer.gov/studies/tus-cps/TUS-CPS overlap.pdf (accessed 15 May 2008).

30. Gilpin EA, Pierce JP, Cavin SW, et al. Estimates of population smoking prevalence: self vs proxy reports of smoking status. Am J Public Health 1994;84:1576-9.

31. Efron B. The jackknife, the bootstrap and other resampling plans. Philadelphia: Society for Industrial and Applied Mathematics, 1982.

32. SAS Institute Inc. SAS 9.1 Language Reference: Concepts. Cary, NC: SAS Institute, Inc, 2004.

33. Research Triangle Institute. SUDAAN Language Manual, Release 9.0 Research Triangle Park, NC: Research Triangle Institute, 2004.

34. Furberg $\mathbf{H}$, Lichtenstein P, Pedersen NL, et al. Cigarettes and oral snuff use in Sweden: Prevalence and transitions. Addiction 2006;101:1509-15.

35. International Agency for Research on Cancer. Smokeless tobacco and some tobacco-specific N-nitrosamines. IARC Monographs on the Evaluation of Carcinogenic Risks to Humans. Vol 89. Lyons, France: International Agency for Research on Cancer, 2007. PDF file, http://www.iarc.fr/cgi-bin/htsearch (accessed 15 April 2008).

36. Levy DT, Mumford EA, Cummings KM, et al. The relative risks of a low-nitrosamine smokeless tobacco product compared with smoking cigarettes: estimates of a panel of experts. Cancer Epidemiol Biomarkers Prev 2004;13:2035-42.

37. O'Connor RJ. Smokers' beliefs about the relative safety of other tobacco products: findings from the ITC collaboration. Nicotine Tob Res 2007;9:1033-42.

38. Kozlowski L. Effects of smokeless tobacco product marketing and use on population harm from tobacco use: Policy perspective for tobacco-risk reduction. Am J Prev Med 2007;33(6S):S379-86.

39. Orzechowski W, Walker RC. Tax burden on tobacco (2000), (2001) (2002), and (2003). Economic Research Service, USDA. US Centers for Disease Control and Prevention (CDC), State Tobacco Control Highlights (2001), (2002), and (2003).

40. Federal Trade Commission. Smokeless tobacco report for the years 2002-2005. 2007. http://www.ftc.gov/reports/tobacco/02-05smokeless0623105.pdf laccessed 15 May 2008).

41. Centers for Disease Control and Prevention (CDC). State-specific prevalence among adults of current cigarette smoking and smokeless tobacco use and per capita tax-paid sales of cigarettes-United States, 1997. MMWR Morb Mortal Wkly Rep 1998:47:922-6. 